\title{
Will My Patient Benefit from Audiologic Rehabilitation? The Role of Individual Differences in Outcomes
}

\author{
Harvey B. Abrams, Ph.D., ${ }^{1}$ and Theresa Hnath Chisolm, Ph.D., CCC-A ${ }^{2}$
}

\section{ABSTRACT}

Postfitting audiologic rehabilitation (AR) has been a recognized component of the management of hearing-impaired adults since World War II. Despite growing evidence that such interventions as individual auditory training and counseling-based group AR are effective augmentations to amplification, these programs are not commonly implemented in the audiology community. Although research suggests that, on average, patients who engage in AR have improved outcomes compared to those who do not, clinicians have a difficult time determining which of their patients will benefit, if at all, from any particular AR intervention. This article will explore the current literature on auditory training and counseling-based AR in the context of individual variability and those individual factors that are likely to influence postintervention performance. A model of progressive AR, based on patient-identified treatment goals, is proposed to help guide the clinician in making the most appropriate rehabilitative decisions for the patient.

KEYWORDS: Hearing loss, adults, audiologic rehabilitation, aural rehabilitation

Learning Outcomes: As a result of this activity, the participant will (1) describe the strength of the evidence supporting the effectiveness of auditory training and counseling-based group audiologic rehabilitation, (2) list the factors that are most likely to influence postintervention performance, and (3) describe the Progressive Audiologic Rehabilitation model.

Despite impressive advances in hearing aid technology over the past several decades, many hearing aid users continue to experience difficulty in less than optimal listening
${ }^{1}$ Starkey Hearing Technologies, Eden Prairie, Minnesota; ${ }^{2}$ Department of Communication Sciences and Disorders, University of South Florida, Tampa Florida.

Address for correspondence: Harvey B. Abrams, Ph.D., Starkey Hearing Technologies, 6600 Washington Ave S., Eden Prairie, MN 55344 (e-mail: harvey_abrams@starkey. com).
Individual Variability in Aided Outcomes; Guest Editor, Jason A. Galster, Ph.D.

Semin Hear 2013;34:128-140. Copyright (C) 2013 by Thieme Medical Publishers, Inc., 333 Seventh Avenue, New York, NY 10001, USA. Tel: +1(212) 584-4662. DOI: http://dx.doi.org/10.1055/s-0033-1341349.

ISSN 0734-0451. 
conditions. This problem is often experienced among older listeners whose speech understanding is compromised by both a loss of audibility and associated age-related cognitive changes affecting their working memory and speed of processing. ${ }^{1}$ Because hearing aid use alone does not fully restore an individual to prehearing loss function, there is a need for a holistic approach to adult audiologic rehabilitation (AR) that goes beyond device use. Adult AR approaches can trace their origins to the military audiology programs established in response to the hearing healthcare needs of World War II veterans, which included auditory and visual speech perception training and vocational and psychological counseling in addition to the fitting of hearing aids. ${ }^{2}$ In current practice, there are two general approaches to post-hearing aid fitting adult AR. One is to provide auditory and/or auditory-visual speech perception training, ${ }^{3,4}$ currently typically implemented in computer-based programs, ${ }^{5}$ and the other is the provision of educational counseling, most often in post-hearing aid fitting group sessions. ${ }^{4,6}$ Although systematic reviews of both auditory speech perception training $^{3,4}$ and group counseling ${ }^{4,6}$ confirm the effectiveness of these AR interventions for improving speech understanding and reducing the self-perception of activity limitations and participation restrictions, respectively, there is considerable individual variability associated with the outcomes of each approach. To date, there has been scarce attention paid to the factors that might help to explain the source of this variability. The purpose of this article is to examine possible causes for the variability in outcomes associated with postfitting individual auditory training and counseling-based group $\mathrm{AR}$ programs and to suggest strategies to better optimize those outcomes.

\section{INDIVIDUAL AUDITORY TRAINING}

Auditory training (AT) refers to a category of interventions designed to improve speech recognition through the implementation of exercises that range from a focus on small units of speech (phonemes or syllables) to larger elements of speech (sentences or phrases). These are often referred to, respectively, as analytic or synthetic AT approaches. A combination of these two approaches was the primary rehabilitative approach provided to returning veterans following World War $\mathrm{II}^{2}$ and has been modified throughout the 20th and 21st centuries to adapt to and take advantage of changing technologies as exemplified by computer-assisted training programs, some of which can be accessed via the Internet. $^{7}$ A typical analytic training task for a listener might involve identifying a token nonsense syllable or word among other "foils" that become increasingly phonetically similar to the token as the patient's performance improves. Synthetic training tasks might require the listener to repeat a sentence in a background of noise. As the patient's performance improves, the signal-to-noise ratio decreases. The assumption is that improved task performance will generalize to improved speech understanding in the patient's day-today communication situations.

Chisolm and Arnold ${ }^{4}$ recently completed a systematic review and meta-analysis of high quality research studies examining the efficacy of AT in adults with hearing loss. The focus of the review was the effect of training on speech recognition performance. Building on a previous systematic review of adult AT in which six studies $^{3}$ were identified as meeting criteria for inclusion, such that they (1) used a randomized controlled trial, cohort, or a before-and-after study design, with or without a control group; (2) included adult subjects with hearing loss who were not users of cochlear implants; and (3) used either objective or standardized subjective outcome measures assessing communication skills, an additional four studies were identified. The 10 studies summarized in Table $1,^{8-18}$ varied in terms of training paradigms, number of subjects, methodological quality, and statistically significant results. Although the metaanalysis revealed a small, but reliable effect size of 0.35 (95\% confidence interval $[\mathrm{CI}]=0.13$ to $0.58)$, Cohen's $d$ effect sizes for the individual studies were quite varied, with relatively large confidence intervals, as shown in Table 1 . The $95 \%$ confidence interval suggests that if the studies were repeated on the same population, the new outcomes would fall within this range $95 \%$ of the time. If the confidence interval includes 0 , the data fail to reach statistical 


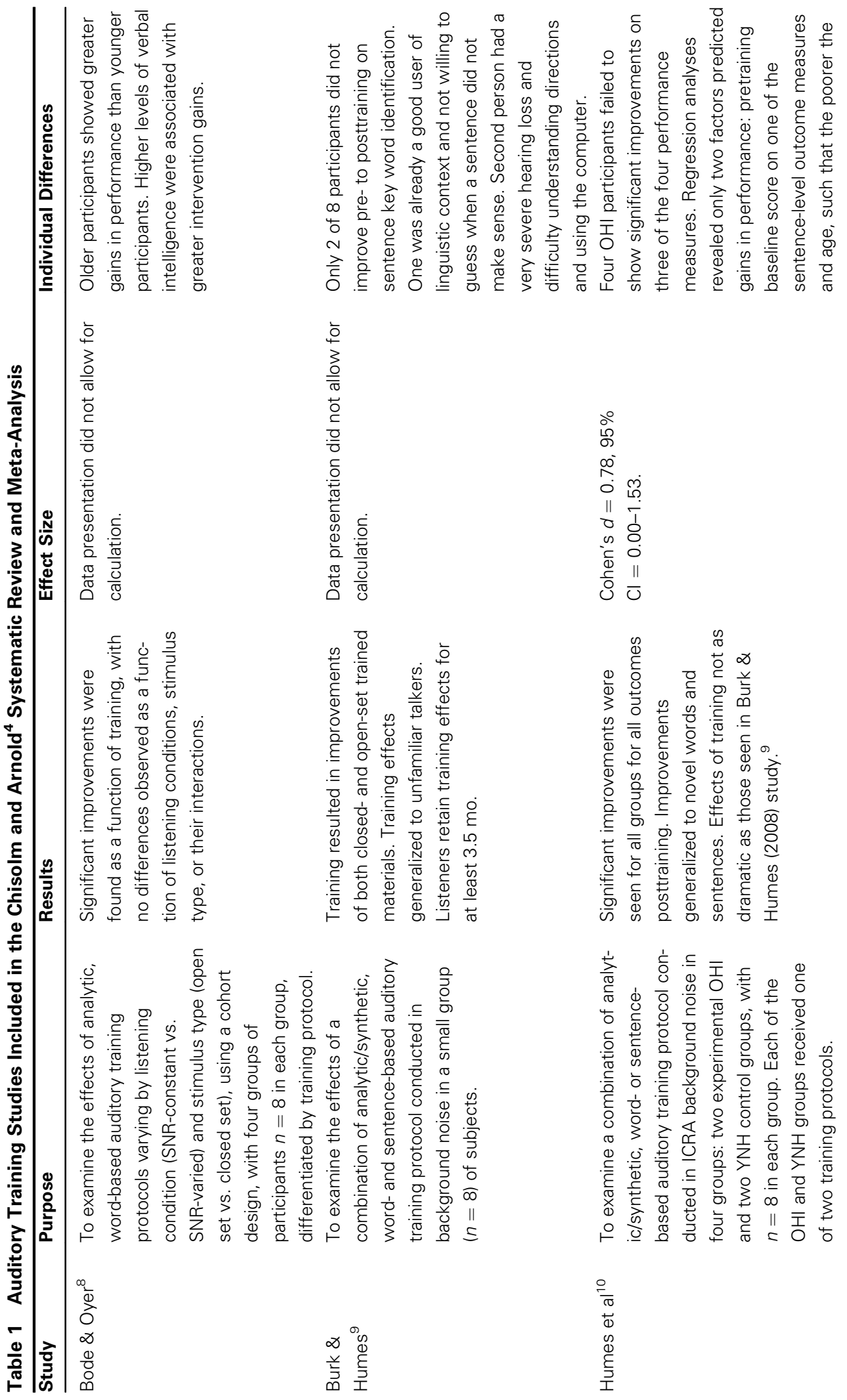




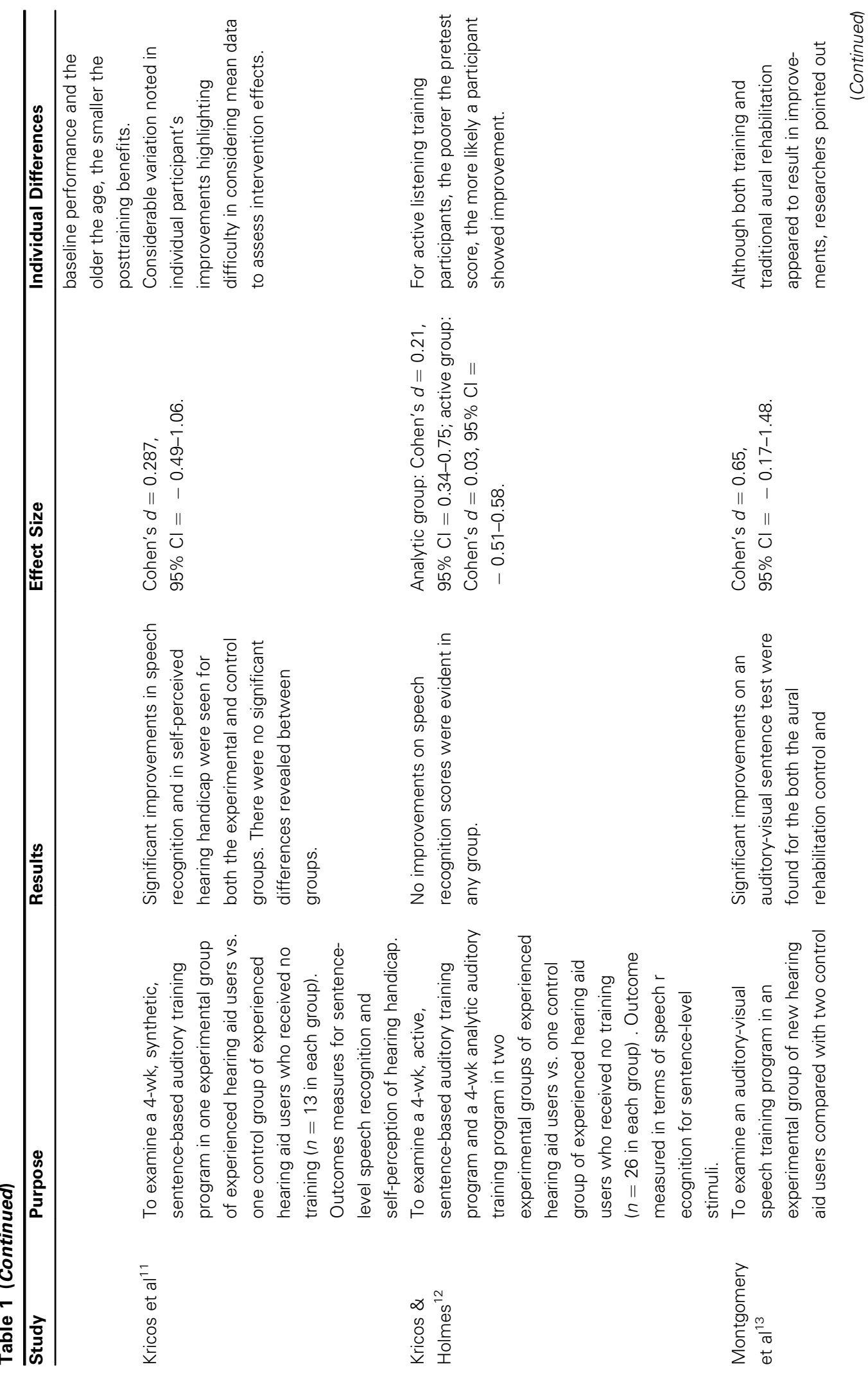




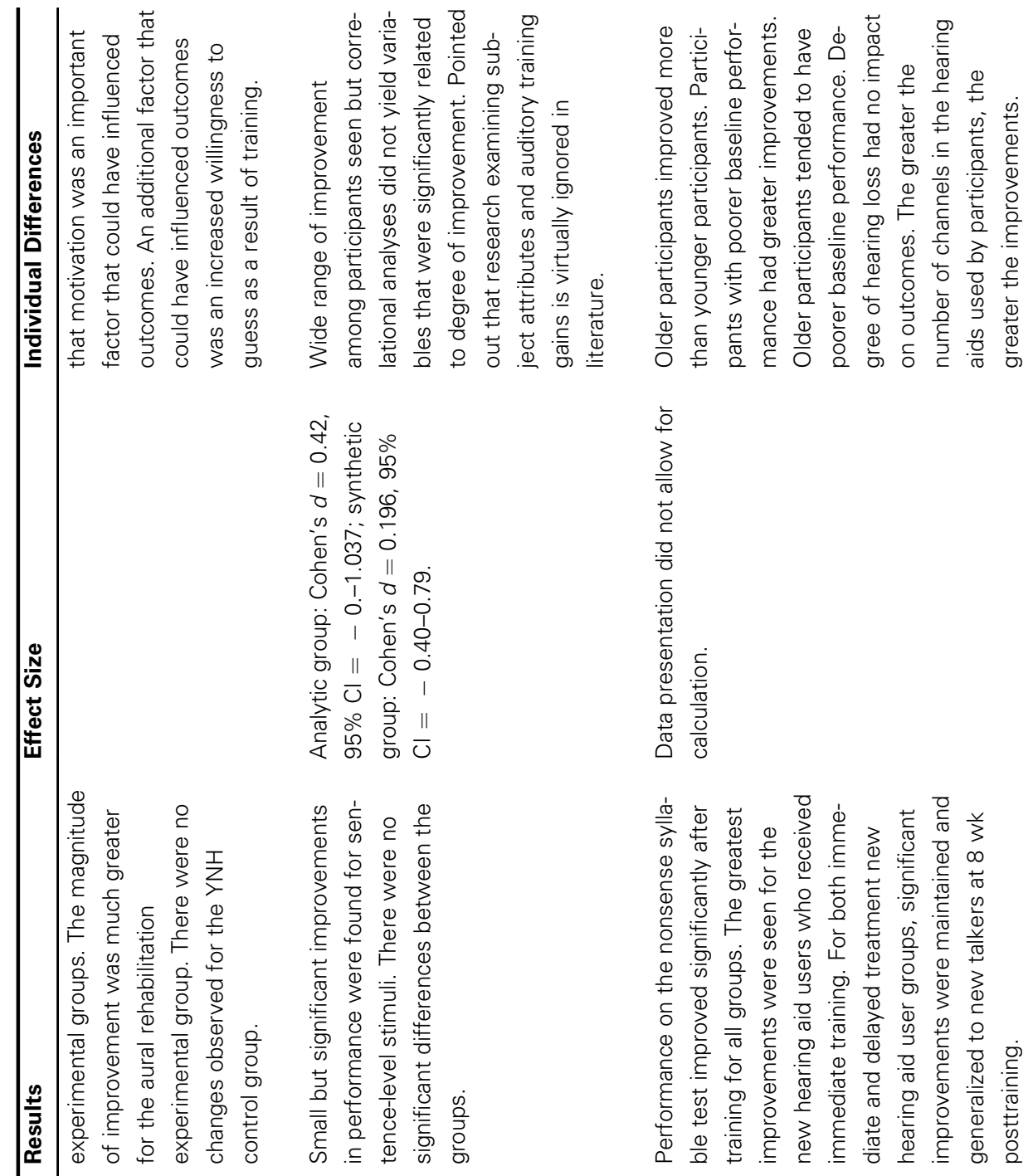

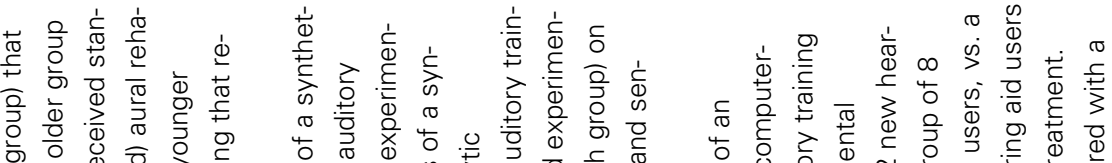

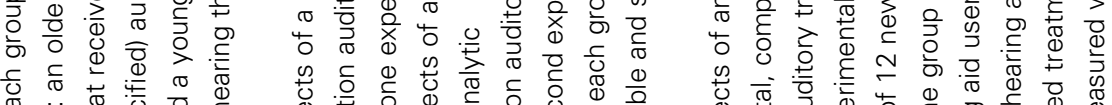

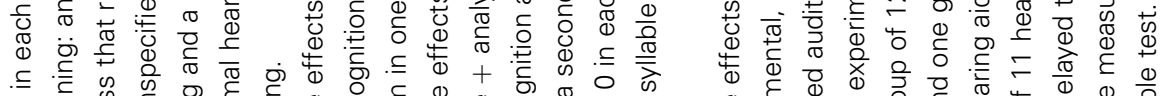

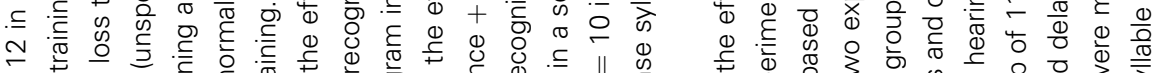
II 0 .

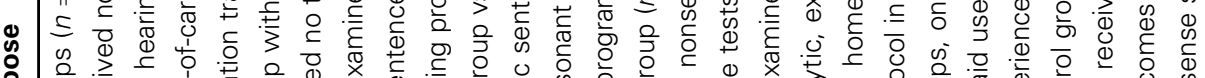

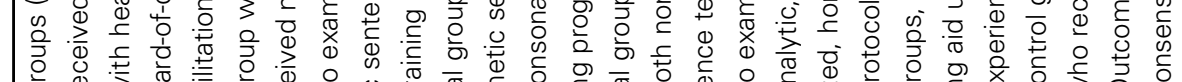

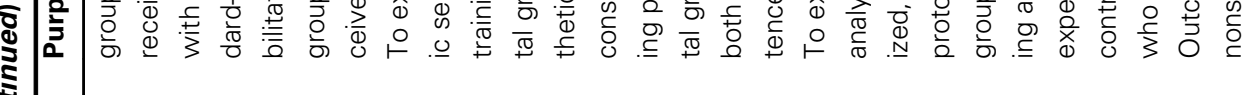

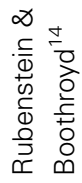
$\frac{\circ}{\pi}$ 


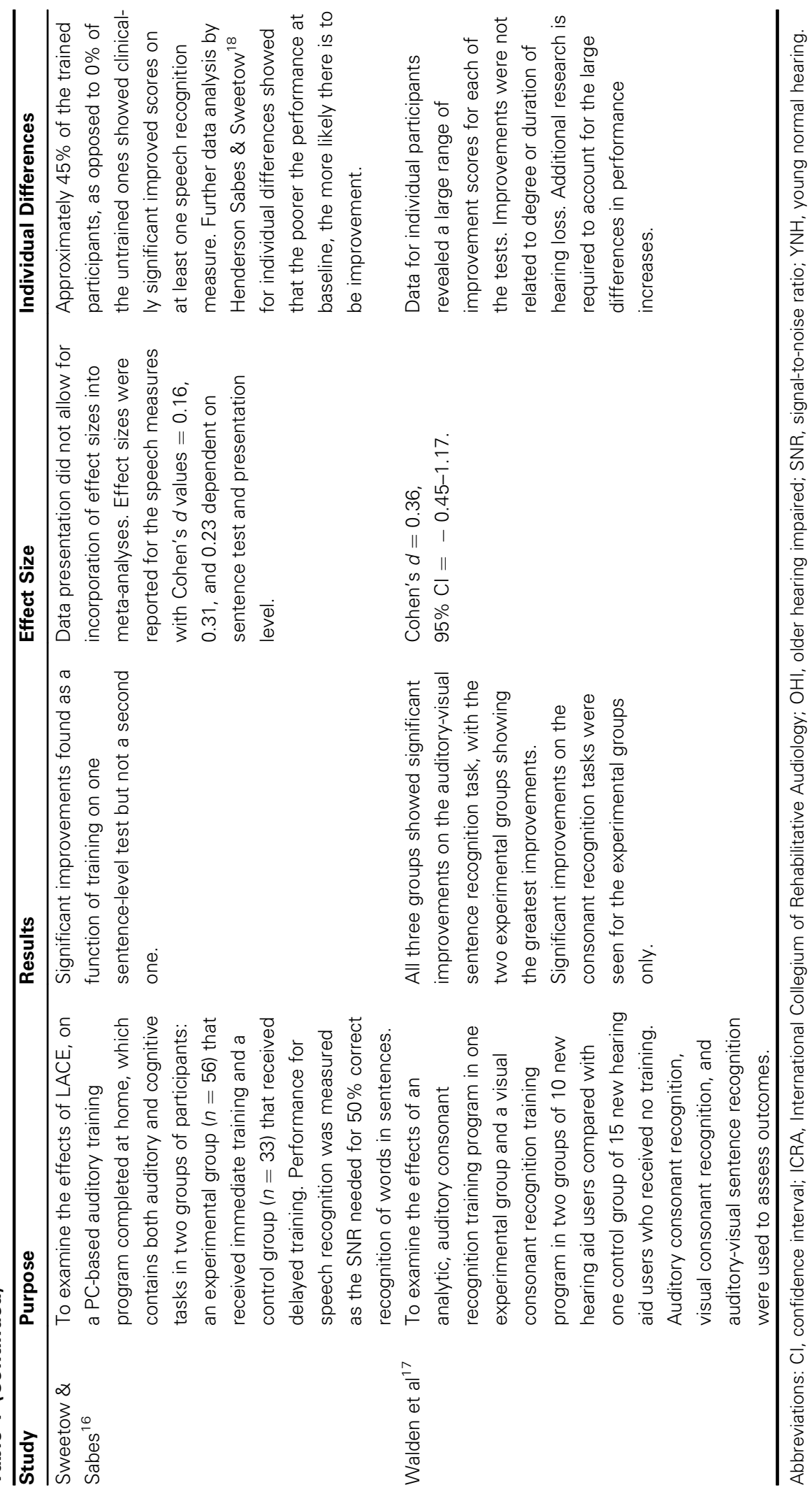


significance. Effect size, on the other hand, is a measure of practical significance; the greater the effect size, the more likely the intervention is to have an impact, on average, for individuals. These findings led Chisolm and Arnold ${ }^{4}$ to conclude that although AT, in general, will likely lead to an improvement in speech understanding for the average patient, there is a need for AT paradigms to be optimized for the individual.

\section{COUNSELING-BASED GROUP AR}

Chisolm and Arnold ${ }^{4}$ also conducted a systematic review and meta-analysis for the body of work examining the effects of counseling-based group AR. This approach to AR attempts to improve patient outcomes through group discussion and education as implemented via a counseling-based approach with an emphasis on information and psycho-social adjustment. ${ }^{19,20}$ Although such programs differ in specific content, they generally address such areas as understanding communication problems associated with hearing loss, use of strategies for managing difficult situations, coping strategies, problem solving, assertiveness training, and quality of life (QoL). ${ }^{20,22}$ To conduct the review, Chisolm and Arnold ${ }^{4}$ began with Hawkins $^{21}$ systematic review of counselingbased group AR programs, which was completed in 2005. Although Hawkins accepted studies with outcome measures focused on perceived hearing aid benefit and/or satisfaction, personal adjustment, or perceived hearing handicap and/ or QoL, Chisolm and Arnold ${ }^{4}$ only included studies that assessed the effects of intervention on self-perception of hearing handicap as measured with disease-specific instruments and/or QoL as measured with generic instruments. In addition, studies were limited to those that used a randomized control trial. Seven studies reviewed by Hawkins ${ }^{21}$ were found to meet these criteria and an additional two studies were identified through searching more recent publications. The nine studies are summarized in Table $2 .{ }^{19,20,22-28}$ Similar to the conclusion drawn by Hawkins that "one does not see overwhelming evidence to support the benefits of group AR programs." ${ }^{21}$ Chisolm and Arnold ${ }^{4}$ concluded that there was not conclusive support for group AR intervention when only individual study results were considered. However, when the individual study findings were combined through meta-analysis, a standardized mean difference of -0.35 (95\% CI $=$ -0.48 to -0.022 ) was found, indicting a small, but reliable, improvement in the selfperception of improvements in outcomes related to hearing handicap and/or QoL as a result of group AR. Note that negative values for this meta-analysis reflect a reduction in hearing handicap (i.e., postintervention benefit). As with AT, Cohen's $d$ effect sizes for the individual studies were quite varied, with relatively large confidence intervals, as shown in Table 2. Thus, Chisolm and Arnold ${ }^{4}$ again concluded that there was a need for examining individual needs in determining the optimal intervention approach.

\section{MATCHING INTERVENTION TO INDIVIDUAL DIFFERENCES: WHAT CAN WE LEARN FROM THE LITERATURE?}

As a first step in developing criteria that might guide us in identifying which patients might benefit from which types of AR intervention, the studies included in the Chisolm and Arnold $^{4}$ systematic review were examined to identify potential influences of individual differences on outcomes. The last columns of Table 1 and Table 2 summarize the points made in each of the studies as a result of considering either individual data and/or the pattern of responses. Several themes emerge and each is discussed below.

Baseline performance: First, it was noted in several studies that the poorer the baseline performance, the more likely that improvement will occur. ${ }^{10,12,15-17}$ Across the studies reviewed in Tables 1 and 2, baseline performance appears to be the most consistent indicator of posttraining benefit.

Age: Data from several studies suggested that older subjects tended to improve more than younger subjects. ${ }^{8,15}$ Some reasons posited for this observation include the fact that the older participants in these studies had poorer baseline scores ${ }^{15}$ and a higher level 


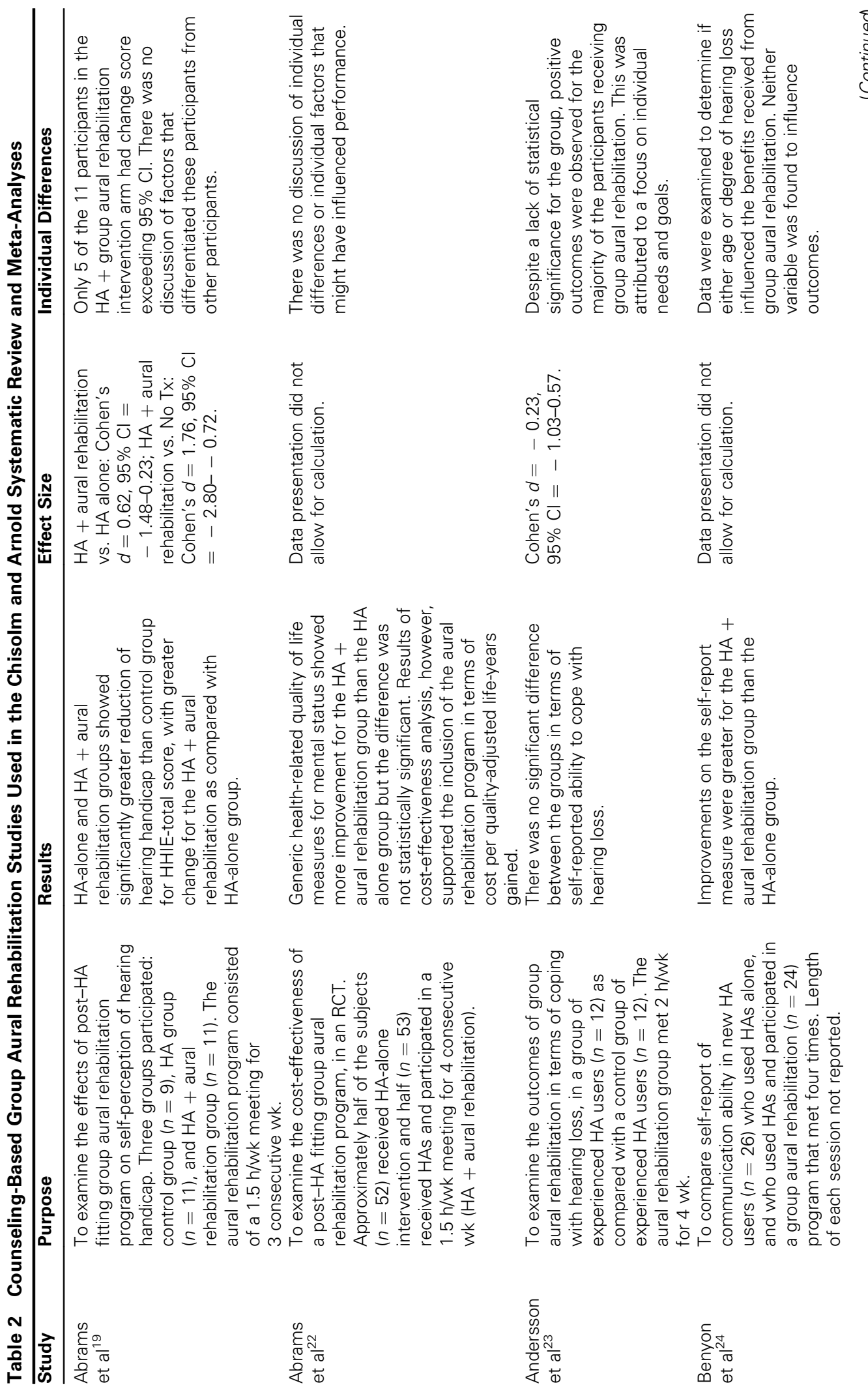




\begin{tabular}{|c|c|c|}
\hline \multicolumn{3}{|l|}{ 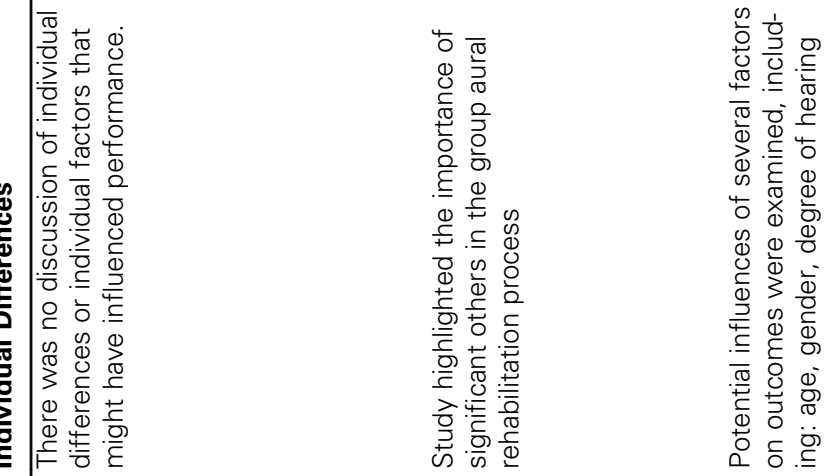 } \\
\hline 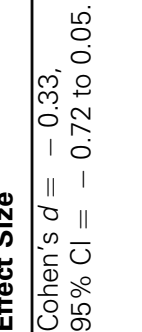 & 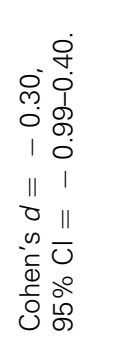 & 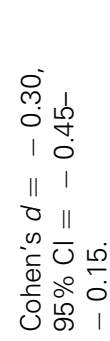 \\
\hline
\end{tabular}

\section{(2)}

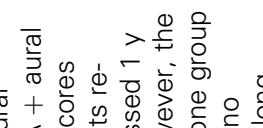

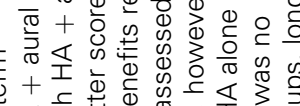

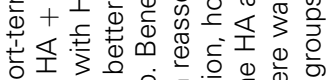

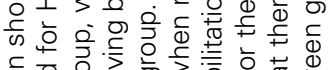

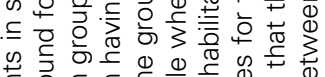

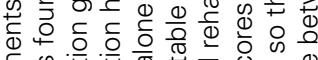

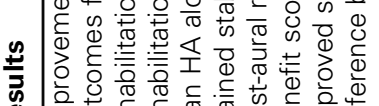

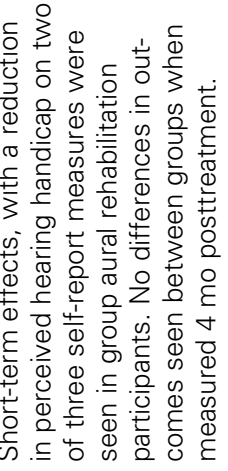

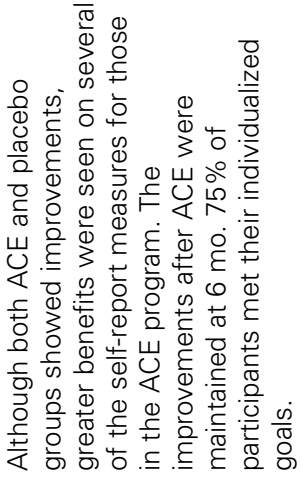

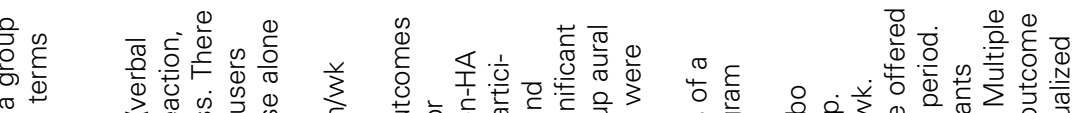

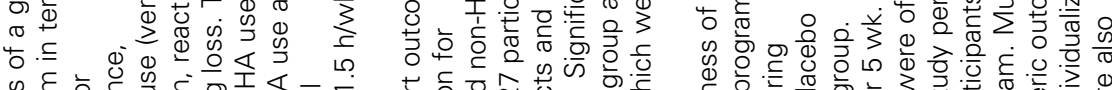

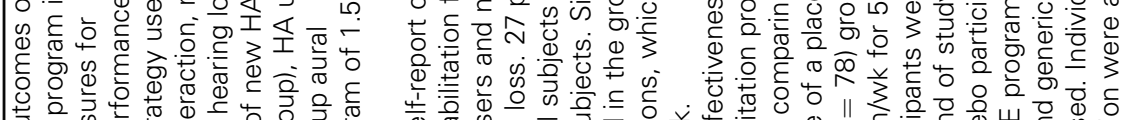

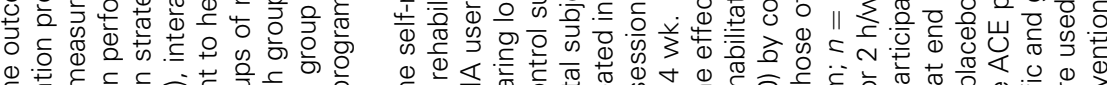

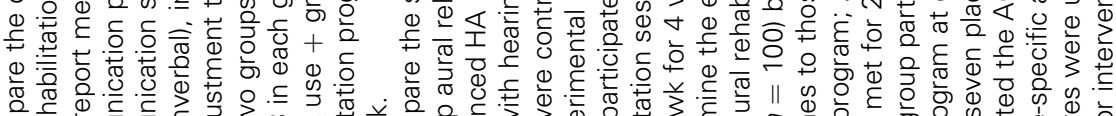

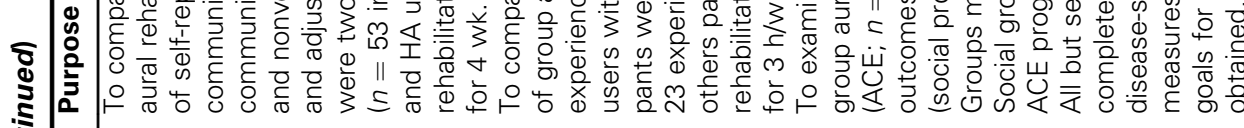

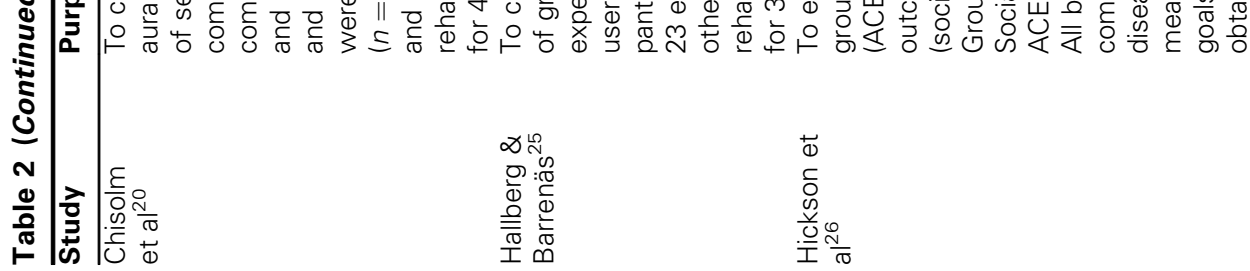




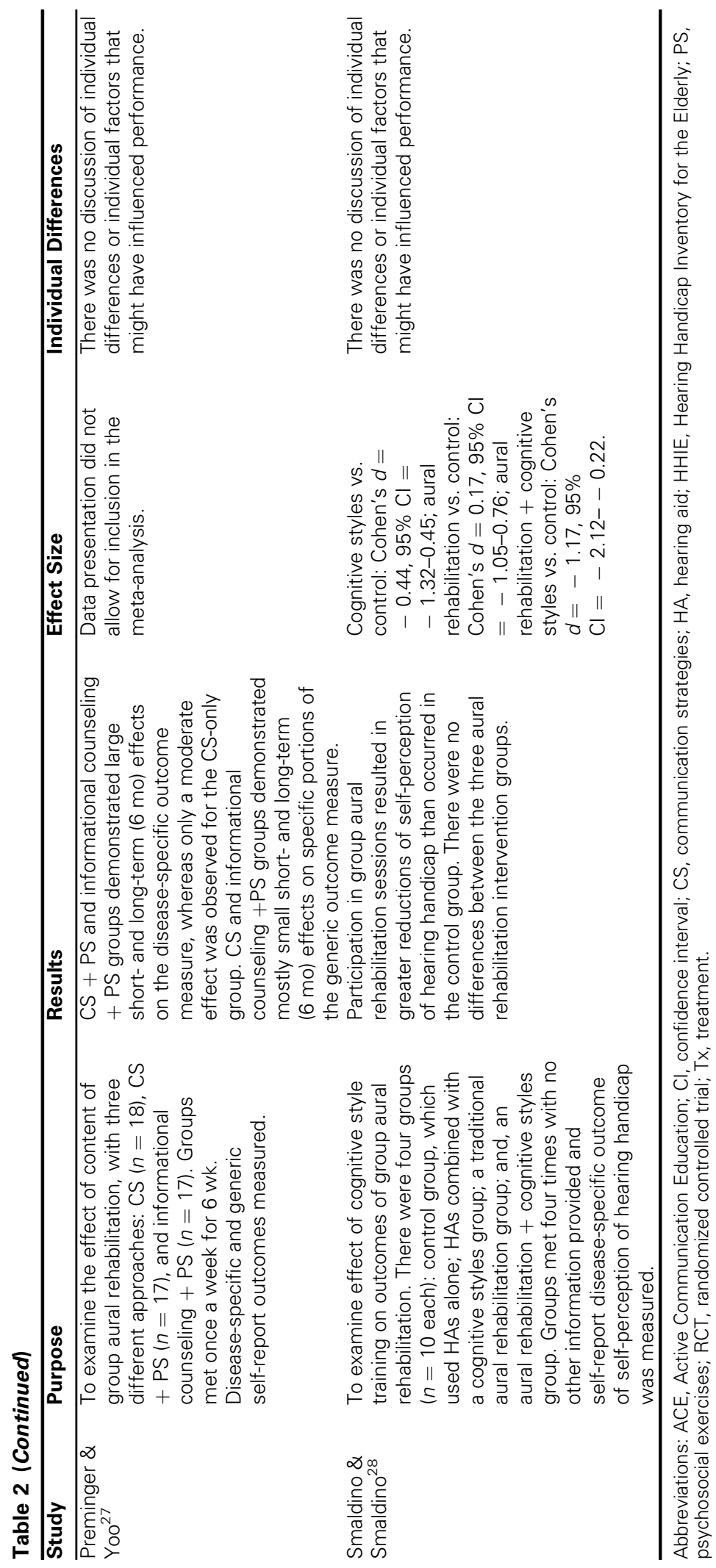


of motivation ${ }^{16}$ as indicated by the fact that the older participants completed the training sooner than younger participants. This relationship was not consistently found, however, as several investigations failed to find an association between age and improved outcomes. ${ }^{10,24,26}$

Hearing loss: Hearing loss severity did not appear to be a factor in predicting posttraining performance. ${ }^{15,17,24,26}$

Other variables: Other factors that may influence postintervention benefit include verbal intelligence, ${ }^{8}$ motivation, ${ }^{13,16}$ increased willingness to guess, ${ }^{13,14}$ and the involvement of a significant other in the AR process. $^{25}$

It should be noted that many of the studies cited in Tables 1 and 2 did not address the issue of individual differences at all. Further research examining individual factors that are likely to influence postintervention performance remains an important field of study. Given the limited information currently available, how can the clinician advise their patients concerning the most appropriate postfitting AR intervention?

\section{PROGRESSIVE AUDIOLOGIC REHABILITATION: A PRACTICAL APPROACH TO AR}

How does the clinician decide which of their patients is most likely to benefit from a specific type of AR intervention? Unfortunately, given the issues associated with individual variability discussed thus far, it appears that other than baseline performance on outcome measures, there are not specific demographic or audiometric measures that are particularly predictive. We propose a progressively intensive approach to AR based on specific patient needs to guide the clinician toward the appropriate level of rehabilitative intervention. There is some evidence to support this approach, as shown by Andersson and colleagues who found that a group AR approach was effective if it focused on individualized goals. ${ }^{23}$ In our own work we have found that a focus on individualized goals leads to success in the use of FM technology ${ }^{29}$ and a progressive approach has been successful in tinnitus management. ${ }^{31}$ With regard to FM systems, Chisolm and colleagues ${ }^{29}$ were able to demonstrate successful and long-term FM use and satisfaction among a group of hearing-impaired adults, experiencing limited success with their current hearing aids, when the decision to fit an FM device was made on the basis of specific, patient-identified goals as determined through the use of the Client Oriented Scale of Improvement (COSI). ${ }^{30}$ Those goals identified situations in which FM technology would likely provide an advantage over their optimized hearing aids. In the tinnitus treatment domain, a progressive audiologic tinnitus management approach has been described by Henry and colleagues ${ }^{31}$ that is designed to deliver the least intensive intervention initially (e.g., audiologic evaluation and counseling) and progresses though increasingly more intensive intervention to include group education, tinnitus evaluation, tinnitus management (sound therapy, cognitive behavioral therapy), and, finally, referral to mental health specialists if indicated.

A similar approach can be applied to audiologic rehabilitation. A proposed model for Progressive Audiologic Rehabilitation (PAR) is illustrated in Fig. 1. PAR is characterized by the administration of commonly used rehabilitative strategies that range from least intensive (level 1) to most intensive (level 5). Intensity, in this context, refers to the amount of time and energy the patient is willing to invest in his or her own rehabilitation and will likely be influenced by the impact of the patient's hearing impairment on his or her self-perceived activity limitation and participation restriction. We do not suggest that a patient necessarily progresses, stepwise, from the lowest to highest level. Depending upon patient needs, treatment goals, and degree of success, a patient may be assigned to any level along the intervention continuum, move up or down, or be assigned to different levels simultaneously. A critical component required for the success of PAR is the identification of specific, patient-defined goals as might be implemented through the use of the COSI. ${ }^{30}$ The following scenario illustrates how the PAR might be employed: 


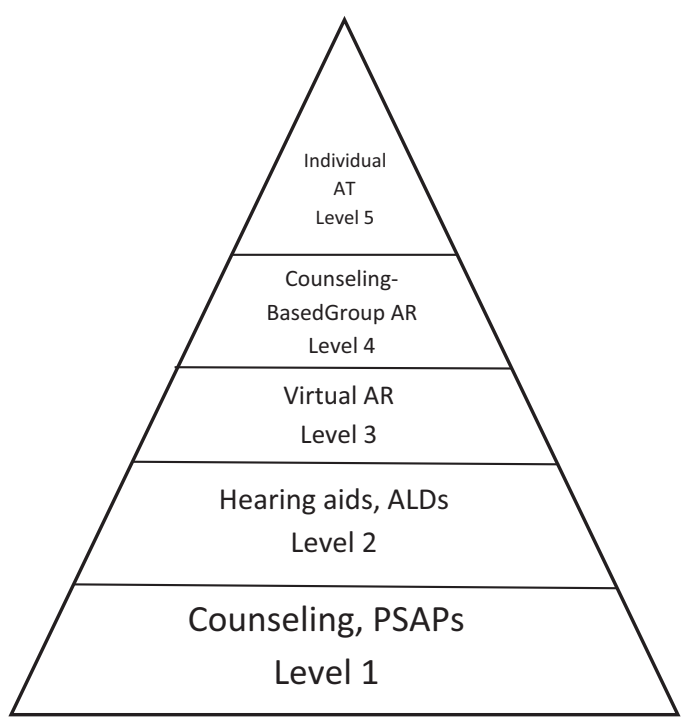

Figure 1 A proposed Progressive Audiologic Rehabilitation (PAR) model progressing from least intensive (Level 1) to most intensive (Level 5). Examples of associated interventions are identified at each level.

J.S., a 67-year-old retired public school teacher, complains that he has to turn up the TV louder than his wife would prefer. He denies any difficulty understanding his wife and, as the couple is not particularly socially active, he denies any other significant communication problems. J.S.'s primary (and only) treatment goal is to be able to hear and understand the TV at a volume level that is comfortable for his wife. To meet the patient's goal, you provide him with a personal sound amplification product designed for the TV and counsel him and his wife concerning best communication practices (level 1). You check back with J.S. in a couple of weeks and he is delighted with the TV amplifier, as is his wife-J.S.'s treatment goal has been satisfactorily achieved.

J.S. returns 5 years later with complaints of increasing communication problems. He and his wife have moved into a retirement complex and he wants to take part in the many social events that the center offers but he is finding it almost impossible to participate in most of the activities due to his hearing problems. On the basis of his audiologic evaluation and stated COSI goals (reduce the number of times he has to ask for repetition in one-on-one situations; improve ability to understand others in the dining room), you select and fit J.S. with appropriate hearing instruments with the potential to add remote microphone or FM technology in the future (level 2). J.S. and his wife return for their 30-day follow-up and, although the patient reports considerable improvement in one-on-one situations, he is still struggling to keep up with conversations in small groups such in the dining room where he and his wife share a table with another couple. At this point, you instruct J.S. on a Web-based AT program that he can access from his home computer (level 3-J.S. is computer savvy) and enroll J. S. and his wife in a counseling-based AR program (level 4) conveniently held at their retirement center, where they will participate with other individuals to better understand the dynamics of hearing loss and learn strategies to improve their communication effectiveness.

At the conclusion of the group AR sessions and after completing the Web-based AT program, J.S. returns for a 3-month follow-up. $\mathrm{He}$ has noticed considerable improvement communicating with his dining room companions and in other small groups. He has gained confidence in his communication abilities to the extent that he and his wife are taking bridge lessons. J.S. reports that, although he still has some difficulty in large groups when many people are talking at once, his treatment goals have been satisfactorily achieved. You remind him that there are still additional treatment options available, such as remote microphone technology and individual AT (level 5), in the event that his communication demands increase or he experiences deterioration in his hearing abilities.

\section{SUMMARY AND CONCLUSIONS}

Currently available research shows that, as pointed out in 1987 by Rubinstein and Boothroyd,${ }^{14}$ the role of individual differences has not been adequately explored. What little attention has been paid to individual differences appears to highlight baseline performance and or baseline needs as the primary determinant of who might benefit. From a clinical perspective, assessing individual goals and matching treatment alternatives to meet those goals as suggested by the PAR model proposed here is a realistic approach. Future studies are needed to assess the effectiveness of the model.

\section{REFERENCES}

1. Pichora-Fuller MK, Souza PE. Effects of age on auditory processing of speech. Int J Audiol 2003; 42:11-16 
2. Bergman M. On the origins of audiology: American wartime military audiology. Audiol Today 2002; Monograph 1

3. Sweetow R, Palmer CV. Efficacy of individual auditory training in adults: a systematic review of the evidence. J Am Acad Audiol 2005;16:494-504

4. Chisolm T, Arnold M. Evidence for the effectiveness of aural rehabilitation programs in adults. In: Wong L, Hickson L, eds. Evidence Based Practice in Audiology. San Diego, CA: Plural Publishing; 2012:237-266

5. Pichora-Fuller MK, Levitt H. Speech comprehension training and auditory and cognitive processing in older adults. Am J Audiol 2012;21:351-357

6. Hawkins DB. Effectiveness of counseling-based adult group aural rehabilitation programs: a systematic review of the evidence. J Am Acad Audiol 2005;16:485-493

7. Sweetow RW, Sabes JH. Technologic advances in aural rehabilitation: applications and innovative methods of service delivery. Trends Amplif 2007; 11:101-111

8. Bode DL, Oyer HJ. Auditory training and speech discrimination. J Speech Hear Res 1970;13:839-855

9. Burk MH, Humes LE. Effects of long-term training on aided speech-recognition performance in noise in older adults. J Speech Lang Hear Res 2008;51:759-771

10. Humes LE, Burk MH, Strauser LE, Kinney DL. Development and efficacy of a frequent-word auditory training protocol for older adults with impaired hearing. Ear Hear 2009;30:613-627

11. Kricos P, Holmes A, Doyle D. Efficacy of a communication training program for hearing impaired elderly adults. J Acad Rehab Audiol 1992; 25:69-80

12. Kricos PB, Holmes AE. Efficacy of audiologic rehabilitation for older adults. J Am Acad Audiol 1996;7:219-229

13. Montgomery AA, Walden BE, Schwartz DM, Prosek RA. Training auditory-visual speech reception in adults with moderate sensorineural hearing loss. Ear Hear 1984;5:30-36

14. Rubinstein A, Boothroyd A. Effect of two approaches to auditory training on speech recognition by hearing-impaired adults. J Speech Hear Res 1987;30:153-160

15. Stecker GC, Bowman GA, Yund EW, Herron TJ, Roup CM, Woods DL. Perceptual training improves syllable identification in new and experienced hearing aid users. J Rehabil Res Dev 2006; 43:537-552

16. Sweetow RW, Sabes JH. The need for and development of an adaptive Listening and Communication Enhancement (LACE) Program. J Am Acad Audiol 2006;17:538-558

17. Walden BE, Erdman SA, Montgomery AA, Schwartz DM, Prosek RA. Some effects of training on speech recognition by hearing-impaired adults. J Speech Hear Res 1981;24:207-216

18. Henderson Sabes J, Sweetow RW. Variables predicting outcomes on listening and communication enhancement (LACE) training. Int J Audiol 2007; 46:374-383

19. Abrams HB, Hnath-Chisolm T, Guerreiro SM, Ritterman SI. The effects of intervention strategy on self-perception of hearing handicap. Ear Hear 1992;13:371-377

20. Chisolm TH, Abrams HB, McArdle R. Short- and long-term outcomes of adult audiological rehabilitation. Ear Hear 2004;25:464-477

21. Hawkins DB. Effectiveness of counseling-based adult group aural rehabilitation programs: a systematic review of the evidence. J Am Acad Audiol 2005;16:485-493

22. Abrams HB, Chisolm TH, McArdle R. A costutility analysis of adult group audiologic rehabilitation: are the benefits worth the cost? J Rehabil Res Dev 2002;39:549-558

23. Andersson G, Melin L, Scott B, Lindberg P. An evaluation of a behavioural treatment approach to hearing impairment. Behav Res Ther 1995;33:283292

24. Beynon GJ, Thornton FL, Poole C. A randomized, controlled trial of the efficacy of a communication course for first time hearing aid users. Br J Audiol 1997;31:345-351

25. Hallberg LR, Barrenäs ML. Group rehabilitation of middle-aged males with noise-induced hearing loss and their spouses: evaluation of short- and long-term effects. Br J Audiol 1994; 28:71-79

26. Hickson L, Worrall L, Scarinci N. A randomized controlled trial evaluating the active communication education program for older people with hearing impairment. Ear Hear 2007;28:212-230

27. Preminger JE, Yoo JK. Do group audiologic rehabilitation activities influence psychosocial outcomes? Am J Audiol 2010;19:109-125

28. Smaldino S, Smaldino J. The influence of aural rehabilitation and cognitive style disclosure on the perception of hearing handicap. J Am Acad Rehab Audiol 1988;21:57-64

29. Chisolm TH, Noe CM, McArdle R, Abrams H. Evidence for the use of hearing assistive technology by adults: the role of the FM system. Trends Amplif 2007;11:73-89

30. Dillon H, James A, Ginis J. Client Oriented Scale of Improvement (COSI) and its relationship to several other measures of benefit and satisfaction provided by hearing aids. J Am Acad Audiol 1997;8:27-43

31. Henry JA, Zaugg TL, Myers PJ, Schechter MA. The role of audiologic evaluation in progressive audiologic tinnitus management. Trends Amplif 2008;12:188-209 